\title{
A Comparison of the Internationalization of Education in Taiwan and Japan: The Perspective of Elementary School Principals
}

\author{
Ming-Huang $\operatorname{Lin}^{1} \&$ Shan-Hua Chen ${ }^{2}$ \\ ${ }^{1}$ Teacher Education Center, National Chiayi University, Chiayi, Taiwan \\ ${ }^{2}$ Graduate Institute of Educational Administration and Policy Development, National Chiayi University, Chiayi, \\ Taiwan \\ Correspondence: Shan-Hua Chen, Graduate Institute of Educational Administration and Policy Development, \\ National Chiayi University, 62103 Chiayi, Taiwan. Tel: 886-52-263-411, ext 1928. E-mail: \\ shanhua@mail.ncyu.edu.tw
}

Received: October 9, 2013 Accepted: November 29, 2013 Online Published: December 17, 2013

doi:10.5539/ies.v7n1p47 URL: http://dx.doi.org/10.5539/ies.v7n1p47

\begin{abstract}
Due to the increasing need to develop a globalized workforce, like many countries across the globe, Taiwan and Japan have extended the efforts to internationalize education to the elementary-school level. This study focuses on elementary school principals from both countries and explores the importance that these school leaders place on the level and ordering of various factors in the internationalization of education efforts. Using a questionnaire-based research design, a researcher-made instrument was administered to the principals of both countries, and the analytic hierarchy process (AHP) as well as descriptive statistics were used to compare the internationalization of education goals of both countries in terms of the effectiveness of ordering and practical implementation. Afterwards, the study utilized corresponding analysis (CA) to determine the views of the principals of both countries regarding the relationships between the goals and strategies of international education, which are summarized therein. Finally, through the data obtained and resulting discussion, the study offers some suggestions for the educational institutions and educators of both countries related to the implementation of an international education.
\end{abstract}

Keywords: globalization, internationalization, principals of elementary schools, analytic hierarchy process (AHP), corresponding analysis (CA)

\section{Introduction}

Due to the influence of globalization, in an effort to increase the future human resource capabilities of their citizens, governments around the world have begun to view internationalization as an important theme of education policy. Although most current efforts to internationalize education are focused on higher education levels, many countries are extending such efforts into the middle school and even elementary school levels (Bunnell, 2010; Stewart, 2007). At the elementary school level, the intention and focus of international education are to give students early exposure to international contacts, networks, and relationships in order to share knowledge, develop an international perspective, and gain early training and experience in cooperating and/or competing with international partners and competitors. In addition, in the era of globalization, the need also exists to enable students to have an early understanding of regional and global conditions, develop global capabilities, and take on the responsibilities of global citizenship (Adam, 2003; Shaklee \& Baily, 2012; Taylor 1994), all of which can lead toward the promotion of the wider goal of world peace (Schoorman, 2000). Therefore, the case can be made that the earlier students are exposed to international education, the more likely it will be for governments to achieve current and future national and international goals (Stewart, 2008). However, while learning from other cultures, one must also develop a national identity and, as a result, one major goal of international education is to find a balance between the promotion of national goals within a framework emphasizing internationalization and multiculturalism (Nukaga, 2003).

As it is an East Asian hub surrounded by the ocean and one of the four little dragons of Asia's economic development, Taiwan's sense of urgency for implementing international education can be imagined. Indeed, in 2011, the Ministry of Education's Education Policy White Paper was released, highlighting the full implementation of international education policies in elementary and junior high schools. 
Taiwan and Japan are geographically close and maintain close diplomatic relations; each considers the other to be an important member of the international community. As early as 1983, Japan launched a 10-year plan to attract 100,000 foreign students. Although Japan's efforts to promote international education focused on the higher education level, due to the influence of globalization in the last 10 years, both Taiwan and Japan have experienced an increase in the foreign population through marriage and employment channels, resulting in a change in the educational policies' focus; furthermore, because of the high degree of industrial development, both countries have low birth rates, leading to the formation of domestic populations composed of different nationalities and the need to promote international education both to increase domestic student understanding of international affairs as well as to improve the ability of schools to enroll more students. Finally, for both countries, English has become the main foreign language and is used to communicate and interact with other countries.

In 2008, the Asia Society (2008) suggested that all students should have access to a globalization-oriented education and recommended that states across the globe should develop a systematic change in educational systems, starting from elementary school, extending into high school, and including all stakeholders in the internationalization of education. This should include (1) reconfiguring high school graduation requirements so that they incorporate the knowledge and skills related to globalization; (2) linking national education standards with international benchmarks, and learning from more developed countries; (3) expanding the study of world languages; (4) encouraging teachers to develop their abilities in the area of international education through professional development, universities, and/or international organizations; (5) ensuring that student learning experiences are international in nature, including the use of technology, travel, internships, and service learning; and (6) using technology to develop global partnerships. From these recommendations, it can be seen that - in the promotion of international education at the elementary school level - the need to empower students, increase teachers' ability to deliver an international education, institutions' ability to promote it are all important levels to consider in the ultimate effectiveness of international education.

As the key figure at schools, school principals' leadership will consequently influence the effectiveness of the results of international education. Principals must face the differing considerations of the various stakeholders at the student, teacher, institutional, and national levels, all of which will affect the international focus of promoting international education. Thus, this study targets elementary school principals in Taiwan and Japan. One hundred seventeen questionnaires were completed from principals in Taiwan while 79 were completed by principals in Japan. This study will first explore the views of principals from Taiwan and Japan regarding the goals of international education, the various levels involved, and the weight given to each level; according to the weights given to each level, the study will calculate which levels of international education are considered to be the most important and then compare the differences between the two countries. Second, this study presents the views of elementary school principals from Taiwan and Japan regarding the effectiveness of the practical implementation of international education in terms of a variety of levels and sub-items and then compares the two countries in these terms. Finally, the study will show the opinions of elementary school principals from the two countries regarding the goals and appropriate implementation methods of international education, which are listed in a corresponding chart.

\section{Literature Review}

\subsection{Internationalization of Elementary Schools}

The internationalization of education is influenced by economic, technological and scientific trends (Altbach, 2004); however, the globalization and internationalization of education should not only have political and economic goals, but also be an educational goal in and of itself (Svensso \& Wihlborh, 2010). The internationalization of education must include teaching and learning, as these are the core of education (Luxon \& Peelo, 2009).

For the internationalization of education at the higher levels, the most common definition is to integrate internationalism or multiculturalism into the processes of education, research, service, and related institutional sectors (Knight \& de Wit, 1995). In recent research on the internationalization of education, Knight (2005) emphasized its integration into the goals of higher levels of education as well as the functions and processes. The aspects of the practical implementation of international education can be broadly grouped into four areas: (1) transnational flows between teachers and students; (2) curriculum internationalization; (3) international research linkages and open learning programs; an (4) bilateral, regional, and international mutual educational qualifications and recognition (Harman, 2004). The development of international education cannot be confined to a particular country, but should rather transcend the ethnic and national levels and be expanded and developed 
with a global perspective and an open mind as well as in accordance with international standards of education.

To carry out transnational education, personnel training is required that includes international exchanges for students and teachers that cover all stages of education. Most research on international education has been conducted at the higher levels, and little research has been done at the elementary school level; very few studies have been done on the relationship between implementation and effectiveness, although research at this level clearly carries importance.

\subsection{The Development of International Education Policy in Taiwan and Japan}

\subsubsection{The Development of International Education in Taiwan}

In 2001, Taiwan implemented Grade 1-9 Curriculum Guidelines that made "cultural learning and international understanding" one of ten fundamental capabilities, emphasizing that students should understand and appreciate their national and world culture, have a deep sense of the world as a global village, develop their sense of inclusion and tolerance, develop the courage to pursue social justice and ecological security, and become peaceful citizens of the world (Ministry of Education, 2003). In 2004, with the publication of the "2005-to-2008 education policy principles," the Ministry of Education continued its emphasis on expanding the global vision and nurturing the talents of new nationals as one of the policy items (Ministry of Education, 2004).

In 2011, Taiwan's Ministry of Education published its "White Paper of International Education for Primary and Secondary Schools." This paper indicated that globalization is not a trend that can be stopped; the requirements needed to face the social, economic, and rapid technological changes and be competitive demands that the educational needs of Taiwan move toward innovative thinking. Since Taiwan's withdrawal from the United Nations, its ability to participate in international activities has encountered limitations, and its people's understanding of the international community has been very limited.

The white paper on international education policy stressed that education must rethink its position and add international learning elements and goals to elementary and secondary schools in order to enable students - through the process of international education - to understand the international community, develop international attitudes, cultivate a national identity, and attain international literacy, world competitiveness, and the international talents to accept global responsibilities (Ministry of Education, 2011).

The internationalization of education in Taiwan's elementary and secondary schools ranges from curriculum development and teaching to international exchanges, teachers' professional development, the internationalization of schools, and the implementation of these factors. According to the overall results of the implementation of international education outcomes published in 2012, nationally, the managing of "internationalization of schools" held the highest proportion, followed by "curriculum development and teaching," "professional development," and "international exchanges," respectively. From this it can be seen that Taiwan has actively attempted to expand its international perspective and continues to develop the content of education policy while actively conducting the internationalization of education at the elementary and secondary levels.

\subsubsection{The Development of International Education in Japan}

In order to achieve the goals of international cooperation, education, and friendship, in 1983 then-Prime Minister of Japan Nakasone Yasuhiro published the "100,000 Foreign Student Plan." By 2003, the number of international students had reached 100,000 . The foreign student policy was formed primarily in response to the Ministry of Culture's (which merged with the Science and Technology Department in 2001 to form the Ministry of Education, Culture, Sports, Science \& Technology [MEXT]) previous proposals regarding the wisdom of international cooperation, which promote efforts to increase friendship and mutual understanding between Japan and other countries, strengthen the ability of the global community, and at the same time internationalize the socio-economic systems (Okubo, 2000).

In March 1989, the Japanese Ministry of Education published the "Elementary School Teaching Guidelines," and full implementation began in 1992. The goal of the guidelines is to guide and enhance mutual understanding among international students in order to provide students with a preliminary understanding of various cultures, languages, international etiquette, knowledge and education, and-in the process of using information technology and internationalization - cultivate the qualities of international citizens, helping students become both "a Japanese citizen with an international outlook" and "a Japanese citizen who has the trust of the international community." Among these, there is also reference to enhancing students' sense of national identity through the use of the national flag and anthem (MEXT, 1989).

In 1996, the Central Council for Education of the Ministry of Education proposed an Education Consultation 
Report entitled "Outlook on the essentials of education in the 21st century." This report placed particular emphasis on the importance of internationalizing education and required that efforts toward international education begin from the elementary school level, the main contents of which include (1) internationalization and education; (2) enhancement of education for international understanding; (3) the improvement of foreign language education; and (4) improving the education and enrichment of the children of foreign spouses (Lin, 2008). In this way, the report showed that Japan hopes that the internationalization of education can commence early in the elementary level and will utilize a variety of methods and channels to support various forms of international exchange activities.

In 2008, with the hope of recruiting more than 300,000 students by 2020, the Japanese government proposed its "300,000 foreign students plan" (MEXT, 2008). In Japan's international education promotion process, the internationalization of universities began very early, whereas for junior high, senior high, and elementary schools, formal implementation of international education began only after the publication of the "Elementary Learning Essentials Guidebook" (in 1992 for elementary schools, 1993 for junior high schools, and 1994 for senior high schools). In the country's junior and senior high schools and elementary schools, the implementation of international education is generally concentrated in the 2 to 4 hours per week of integrative studies, during which time an integrated curriculum approach to teaching activities and content presentation is used (Lin, 2008). In short, Japan's efforts to promote international education began in the early 1990s and have gradually entered the curriculum and programming levels.

Over the past decade, the internationalization of education has been an important educational innovation theme in both Taiwan and Japan. During the issuance of policies in this area, in addition to emphasizing internationalization, they have also not forgotten to include the aspects of national identity and patriotism. Although still in its early stages, many specific practices have already appeared in the curriculum that allow for the comparison of the promotion of the internationalization of education efforts of Taiwan and Japan.

\subsection{School Implementation of Internationalized Education}

Schoorman (2000) suggested that the framework of the internationalization of education-from the commitment of the educational staff to the principal's leadership and the provision of financial and human resources - can survive the stress of innovative goals. In practice, the internationalization of education can be divided into micro and macro parts. The micro level includes the internationalization of university services, such as offering international student services, improving the information services interface as well as management services, and curriculum development, including languages, learning content and scope, cross-cultural and international programs, and global research, among others. The macro level includes increasing the diversity of staff and students and managing international educational efforts such as study abroad programs, faculty growth, school faculty and staff exchanges, and international network links.

English is currently the dominant language of international communication, and introducing English at the elementary school level is an important part of educational internationalization for non-English speaking countries (Dronker, 1993). For the United Kingdom and the United States, the increase in the Chinese-speaking populations has grown the prevalence of Chinese and other languages (Howe, 2008). The mutual benefits of an international education comes in many forms, including greater student and professional mobility, the development of collective curriculum, and the ability to enter international face-to-face meetings and conduct overseas resource sharing (Fortuijn, 2002). To establish mutually beneficial international partnerships, sister schools can cross international boundaries, expanding faculty and student learning opportunities, promoting collaborative research, and enriching the curriculum as well as student recruitment and fundraising - all of which are common ways to promote the internationalization of education (Zheng, Hinshaw, Yu, Guo, \& Dakley, 2001).

Over the past few years, schools and communities in the United States have begun to reset the direction of education policy so that students can succeed in their studies while equipping them with the abilities to face the future challenges of a globalized world. For every state in the United States, a variety of practical strategies have been proposed for the internationalization of education. Some high schools in Chicago, for example, are offering a range of strategies - from foreign languages to sister school exchanges and videos, from internationalizing the curriculum to attempting to integrate academics and global themes - so that every student not only has four years of foreign language learning, but also has the experience of student exchanges with sister schools around the world. Using videos during the regular classroom hours to link up with sister schools and/or professionals and experts from all walks of life is also a common practice (Stewart, 2008). Another example of such practices is at a university in Boston, which has used short-term visits (4 to 7 days) to enable students to understand multicultural, economic, and political complexities. Before such visits, readings, discussions, and the visits, 
students took notes and organized information; after a few days, the actual inspection of local planners and government officials took place. This is also a way to integrate an international perspective into courses, thereby building international cultural cooperative research relationships to understand the processes involved in globalization (Ail \& Doan, 2006).

In Ohio, for example, Howe (2008) suggested that, during the implementation of internationalization education, schools use 10 feasible strategies: (1) using international standards to evaluate the educational system, including tests to measure the internationalization of students and the school; (2) recruiting the services of an international education advisory committee that will provide citizens with the basic knowledge, capabilities, and opportunities needed to survive in an international community; (3) holding international education summits and, through these meetings, allowing the public to understand the importance of international education; (4) designating regional universities and authentic research programs and curriculum to cooperate with Ohio State University in order to strengthen the internationalization of education at Ohio State University; (5) promoting statewide policies and laws that encourage and establish global education and strengthen the ability of states to issue licenses to native speakers to teach Arabic, Chinese, Japanese, Spanish, and French; (6) obtaining help and funds from the federal government, allowing for statewide planning and action; (7) collaborating with foundations, community, and corporate support; (8) supporting school districts to exchange teachers and engage in experimental programs and educational training; (9) creating a statewide international education network of documents; and (10) creating excitement and momentum around a systematic approach to the promotion of international education and global learning.

Clearly, despite the extensive efforts to implement international education at the university level and the movement of primary education toward these goals, at the student level there is a need to focus on expanding students' international knowledge, inspiring students' interest in international issues, and improving students' fundamental foreign language communication skills. At the institutional level, in order to support the government's internationalization of education policy, schools need to create an internationally diverse learning environment to recruit international students; to achieve these efforts, schools can not only receive funds and grants, but can also improve the competitiveness of school enrollment. At the national level, there is a need to develop in students an appreciation of a variety of cultures and tolerance; however, these steps must also be balanced with the need to learn about one's own culture and the promotion of patriotism (Nukaga, 2003). International education should enable students to have a diverse cultural perspective, identify with their local culture, develop national and international thinking, and simultaneously build students' critical thinking and analytical skills as well as adaptability and sensitivity to different cultures (Gurran, Norman, \& Gleeson, 2008). Therefore, for consolidating teachers' and students' national consciousness, enhancing students' understanding of the local culture is also a practical goal of the internationalization of education in elementary schools.

\section{Methodology}

The purpose of this study is to confirm what goals and objectives are sufficient to obtain the benefits of an internationalized education. Thus, the study will use a hierarchical analysis method-namely, the analytic hierarchy process (AHP) - to calculate the relative weight of importance of various contributing factors. The main purpose of AHP is to systematize complex issues, disassembling larger problems into smaller ones and - through the use of different levels of analysis - solving the problem at hand. In using AHP, one is able organize the ideas and opinions of experts and then allocate weights to each class, effectively achieving a consistent classification scheme and, in combination with other forms of statistical techniques, delving further into the analysis (Satty, 1994).

\subsection{Analytic Hierarchy Process}

In AHP, one puts the main goals of international education on the highest level, while the second level is composed of the secondary goals, where such sub-goals are vested in the main objectives. Through AHP, one can determine the weight of each level and ascertain the level of each sub-goal scores. Using AHP has many advantages, including the ability to (1) directly collect the opinions of experts; (2) calculate the weight of individual factors; and (3) confirm a consistent ratio (Saaty, 1980). Using the views of the principals of both countries regarding relative importance, this study was able to make a comparison and establish the relative weights of the criteria as well compare the views of the principals from the two countries. Through AHP, the induction of the relative weights of attributes was then converted to the positive reciprocal matrix to calculate the relative weight of each factor.

After the establishment of the comparison matrix, a commonly used numerical analysis-namely, the eigenvalue solution - was used to identify vectors and find the weight of important factors. The following formula was used 
(see Figure 1):

$$
\begin{aligned}
& \mathrm{A}=\left[\mathrm{a}_{\mathrm{ij}}\right]\left[\begin{array}{ccccc}
1 & a_{12} & & a_{1 m} \\
a_{21} & 1 & \cdots & a_{2 m} \\
& \vdots & & \ddots & \vdots \\
a_{m 1} & a_{m 2} & \cdots & 1
\end{array}\right] \\
& {\left[\begin{array}{ccccc}
1 & & w_{1} / w_{2} & \ldots & w_{1} / w_{n} \\
w_{2} / w_{1} & 1 & & w_{2} / w_{n} \\
w_{n} / w_{2} & w_{n} / w_{2} & \cdots & 1
\end{array}\right]} \\
& \text { The weight is: } \mathrm{Wi}=1 / \mathrm{m} \quad \sum_{j=\mathbf{1}}^{m} \frac{a_{i j}}{\sum_{k=1}^{m} a_{k j}}
\end{aligned}
$$

Figure 1. Formula to calculate weights

Note: "aij" stands for "row i" and "column j" positive reciprocal matrix; "akj" stands for a normalized "row k"

A pairwise comparison of the matrix of values was developed using the choices participants made on questionnaires. Due to the fact that determining levels requires many factors, when making the pairwise comparisons of the participants, it is difficult to achieve consistency; as such, these values need to be put through a consistency test. Therefore, a Consistency Index (CI) was developed.

An eigenvalue $\lambda_{\max }$ was used to handle consistency and, through the consistency matrix, it was verified whether the contents of the answers achieved consistency, where $\mathrm{CR}<.1$ is considered acceptable. The following formula was used (see Figure 2):

$$
\begin{aligned}
& \mathrm{A} \times \mathrm{K}-\left[\begin{array}{cccc}
1 & a_{12} & \ldots & a_{\perp m} \\
a_{21} & 1 & & a_{2 m} \\
& \vdots & \ddots & \vdots \\
a_{m 1} & a_{m ?} & \cdots & 1
\end{array}\right] \times\left[\begin{array}{c}
w_{1} \\
w_{2} \\
\vdots \\
w_{m}
\end{array}\right]-\left[\begin{array}{c}
w_{1}^{\prime} \\
w_{2}^{\prime} \\
\vdots \\
w_{m}^{\prime}
\end{array}\right] \\
& \lambda_{\max }-(1 / \mathrm{m}) \times\left(\frac{\mathrm{w}_{1}^{\prime}}{\mathrm{w}_{1}}+\frac{\mathrm{w}_{2}^{\prime}}{\mathrm{w}_{2}}+\cdots+\frac{\mathrm{w}_{m}}{\mathrm{w}_{m}}\right) \\
& \mathrm{CI}=\frac{\lambda \max -m}{m-1} \quad \mathrm{CR}=\frac{C I}{R I}
\end{aligned}
$$

Figure 2. Consistency test formula

\subsection{AHP Structure}

The chart depicted in Figure 3 was completed based on the literature review and expert discussions. The whole goals of the internationalization of education are placed in the first column; the second column comprises the student, institutional, and societal levels, with these three levels holding an integral position in the overall framework; the third column is composed of nine items related to the goals of internationalizing education and are sub-items of column 2 categories. 


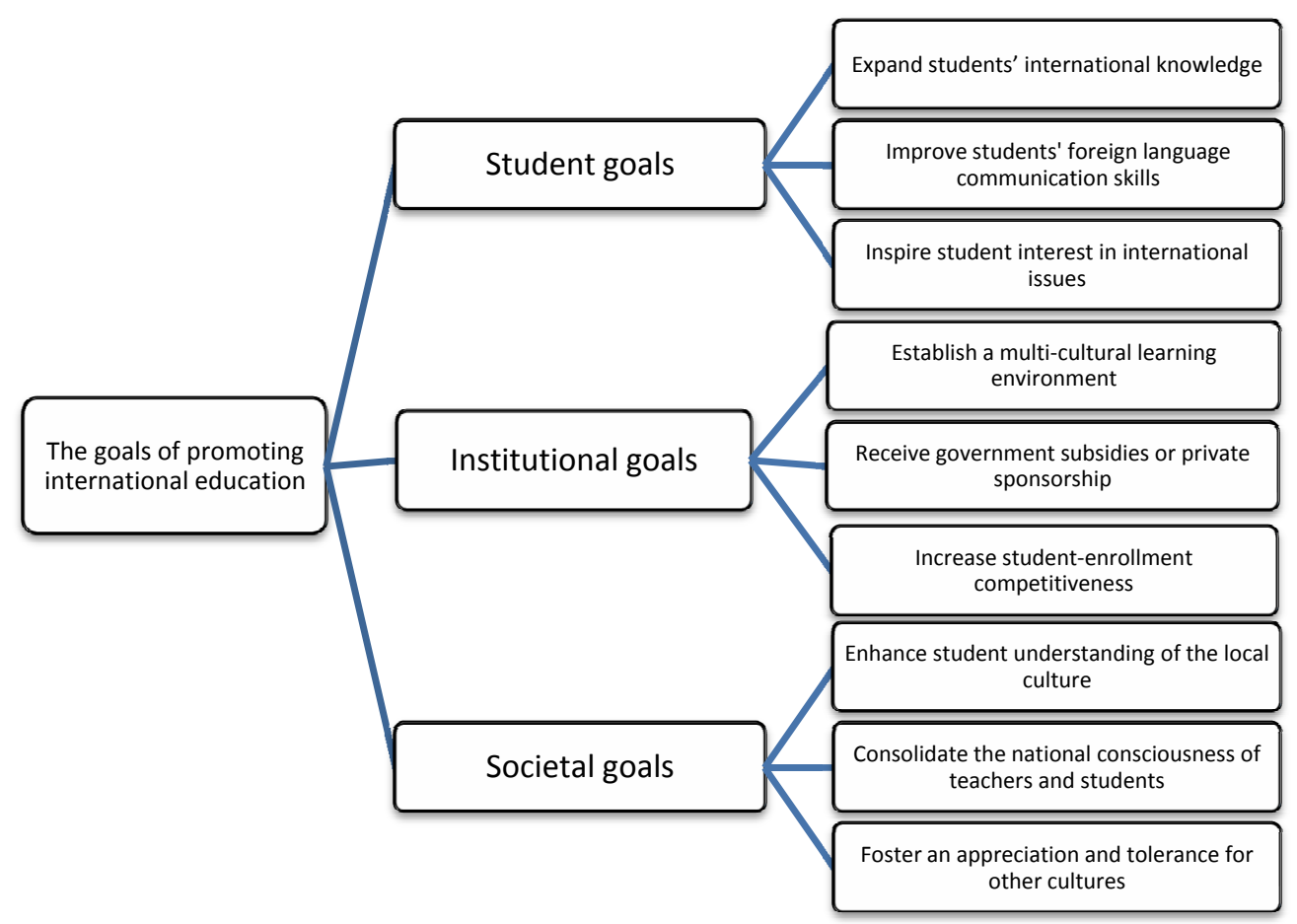

Figure 3. Framework of the goals of promoting internationalization of education at the elementary school level

\subsection{Questionnaire Design}

This study used a researcher-made questionnaire. The questionnaire was designed based on the results of the literature review, and construct validity was established after a full discussion of the content among the research team. The questionnaire consists of two parts. The first part was made by first collecting the choices of the elementary principals on the questionnaires and then calculating the weight placed on the goals of internationalized education at the student, institutional, and societal levels, resulting in nine items (see Figure 3). Principal participants could use these items to complete the pairwise comparisons and then calculate the scores of the goals of each level by weight. These were listed out.

The second part—also a self-questionnaire-listed eight common international education activities that occur in elementary schools: (1) actively recruiting international students, (2) encouraging staff to participate in various international studies, (3) constructing a foreign language learning environment at school, (4) integrating various kinds of international knowledge into the curriculum, (5) establishing cooperative relations with foreign schools, (6) holding overseas study tours or foreign-visitor activities, (7) promoting long-distance exchanges between domestic and international students, and (8) participating in various international competitions. The principals completed the self-assessments of the domestic implementation of internationalizing education.

\subsection{Participants}

Questionnaires were sent to 150 elementary principals each in Taiwan and Japan, 117 of which were returned from Taiwan and 79 from Japan, resulting in a response of $78 \%$ and $52.7 \%$, respectively. As AHP uses expert answers, large numbers are not considered necessary for the first part of the study; however, because the second and third parts do require large numbers, a large number of questionnaires were sent out.

\section{Research Results}

\subsection{Comparing the Perceived Importance of the Various Levels Affected by Internationalization of Education in Taiwan and Japan}

The principals from both countries perceive each level of internationalization of education as carrying specific degrees of importance, as detailed in Table 1. 
Table 1. Comparison of the relative weights of importance held by elementary school principals from Taiwan and Japan of the varying purposes and goals of international education

\begin{tabular}{|c|c|c|c|c|c|c|c|c|c|}
\hline \multirow[b]{2}{*}{ Level } & \multirow[b]{2}{*}{ Sub-level } & \multicolumn{4}{|c|}{ Japan } & \multicolumn{4}{|c|}{ Taiwan } \\
\hline & & $\begin{array}{c}\text { First } \\
\text { level } \\
\text { weight }\end{array}$ & $\begin{array}{l}\text { Raw } \\
\text { Score }\end{array}$ & $\begin{array}{c}\text { Weighted } \\
\text { Score }\end{array}$ & Rank & $\begin{array}{c}\text { First } \\
\text { level } \\
\text { weight }\end{array}$ & $\begin{array}{l}\text { Raw } \\
\text { Score }\end{array}$ & $\begin{array}{c}\text { Weighted } \\
\text { Score }\end{array}$ & Rank \\
\hline \multirow{3}{*}{ Student } & $\begin{array}{l}\text { Expand students' } \\
\text { international } \\
\text { knowledge }\end{array}$ & \multirow{3}{*}{0.33} & 0.28 & 0.09 & 6 & \multirow{3}{*}{0.63} & 0.34 & 0.22 & 1 \\
\hline & $\begin{array}{c}\text { Improve students' } \\
\text { foreign language } \\
\text { communication } \\
\text { skills }\end{array}$ & & 0.32 & 0.11 & 4 & & 0.34 & 0.21 & 2 \\
\hline & $\begin{array}{l}\text { Inspire student } \\
\text { interest in } \\
\text { international issues }\end{array}$ & & 0.40 & 0.13 & 2 & & 0.32 & 0.20 & 3 \\
\hline \multirow{3}{*}{ Institution } & $\begin{array}{c}\text { Establish a } \\
\text { multi-cultural } \\
\text { learning } \\
\text { environment }\end{array}$ & \multirow{3}{*}{0.43} & 0.51 & 0.22 & 1 & \multirow{3}{*}{0.19} & 0.55 & 0.11 & 4 \\
\hline & $\begin{array}{l}\text { Obtain government } \\
\text { subsidies or private } \\
\text { sponsorship }\end{array}$ & & 0.32 & 0.13 & 2 & & 0.19 & 0.04 & 8 \\
\hline & $\begin{array}{l}\text { Improve school } \\
\text { enrollment } \\
\text { competitiveness }\end{array}$ & & 0.17 & 0.07 & 8 & & 0.26 & 0.05 & 6 \\
\hline \multirow{3}{*}{ Society } & $\begin{array}{l}\text { Enhance student } \\
\text { understanding of } \\
\text { the local culture }\end{array}$ & \multirow{3}{*}{0.24} & 0.36 & 0.09 & 6 & \multirow{3}{*}{0.18} & 0.28 & 0.05 & 6 \\
\hline & $\begin{array}{l}\text { Consolidate the } \\
\text { national } \\
\text { consciousness of } \\
\text { teachers and } \\
\text { students }\end{array}$ & & 0.22 & 0.05 & 9 & & 0.17 & 0.03 & 9 \\
\hline & $\begin{array}{c}\text { Foster an } \\
\text { appreciation and } \\
\text { tolerance for other } \\
\text { cultures }\end{array}$ & & 0.42 & 0.10 & 4 & & 0.54 & 0.10 & 5 \\
\hline \multicolumn{2}{|c|}{ Consistency Test } & \multicolumn{4}{|c|}{ C.R. $=0.001(<0.1)$} & \multicolumn{4}{|c|}{ C.R. $=0.015(<0.1)$} \\
\hline
\end{tabular}

Table 1 indicates that, regarding the internationalization of education, Japanese principals give the following weights in order of importance to the institutional (0.43), student $(0.33)$ and societal $(0.24)$ levels, whereas Taiwanese principals give the following weights in order of importance to the student (0.63), institutional (0.19) and societal (0.18) levels. Thus, the Japanese principals placed more emphasis of international education at the institutional level whereas the Taiwanese principals placed more emphasis on students.

\subsection{Comparison of the Sub-Goals of International Education of Taiwan and Japan}

Table 1 provides a comparison of the weights given to the first-level sub-goals. For Taiwan, the highest scores were achieved by three sub-goals: enhance student international knowledge $(0.22)$, improve student foreign language communication skills (0.21), and inspire student interest in international issues (0.20). For Japan, the three highest scores were achieved by the following sub-goals: establish a multicultural learning environment 
(0.22), obtain government subsidies or private sponsorship (0.13), and inspire student interest in international issues (0.13). For Taiwan, the items with the highest scores were mainly concerned with goals related to benefits for students, whereas for Japan, two of the items with the highest scores were at the institutional level, while one was at the student level. Regarding the lower scores of the two countries, for Taiwan the two lowest scores were for consolidate the national consciousness of teachers and students $(0.03)$ and receive government subsidies or private sponsorship (0.04); for Japan, the lowest scores were for consolidate the national consciousness of teachers and students (0.05) and improve school enrollment competitiveness (0.07).

In comparing the two countries, the majority of high scores were obtained in Taiwan. The two items that received a higher score in Japan were to obtain government grants or private sponsors (a difference of 0.07) and improve school enrollment competitiveness (a difference 0.02). These two items are related to the institutional benefits of international education, particularly in terms of obtaining subsidies, because Japan is not currently actively implementing such educational policies; thus, Japanese school principals must consider the difficulties of implementing such policies at the institutional level. The only item where Taiwan and Japan scored no difference in degree of importance (i.e., foster an appreciation and tolerance for other cultures) was ranked in the middle.

\subsection{Taiwanese and Japanese Principals' Perceptions Regarding the Practical Implementation of Internationalizing Education}

Table 2. Taiwanese and Japanese principals' perceptions regarding the practical implementation of internationalizing education

\begin{tabular}{lcccc}
\hline \multicolumn{1}{c}{ International education implementation activities item list } & Japan & Rank & Taiwan & Rank \\
\hline a. Actively recruit foreign students & 1.56 & 5 & 1.28 & 8 \\
b. Encourage staff to attend international education workshops & 2.14 & 3 & 2.47 & 3 \\
c. Establish a school-wide foreign language learning environment & 2.97 & 1 & 3.31 & 1 \\
d. Integrate international knowledge into the curriculum & 2.62 & 2 & 3.18 & 2 \\
e. Establish partnerships with international schools & 1.56 & 5 & 1.64 & 5 \\
f. Hold frequent overseas study tours or visits & 1.44 & 7 & 1.64 & 5 \\
g. Establish domestic and international school exchanges & 1.58 & 4 & 1.80 & 4 \\
h. Join a variety of international competitions & 1.39 & 8 & 1.74 & 7 \\
\hline
\end{tabular}

The findings from Table 2 reveal that Taiwan's three highest scores were c: construct a school-wide foreign language learning environment (3.31), d: integrate a variety of international knowledge into the curriculum (3.18), and b: encourage staff to participate in various international trainings (2.47). Japan's three highest scores in order were c: construct a school-wide foreign language learning environment (2.97), d: integrate a variety of international knowledge into the curriculum (2.62), and b: encourage staff to participate in various international training (2.14). The items and their order were the same for both countries.

In comparing the actual implementation effectiveness of international education of Taiwan and Japan, it can be seen that Taiwan's scores on most items were higher than those for Japan. In terms of the order of implementation, only two items had large differences in Taiwan and Japan-namely, h: participate in various international competitions and a: actively enroll international students. For Taiwan, item "h" was ranked fifth and item "a" was eighth. Conversely, for Japan, item "a" was ranked fifth and item "h" was ranked eighth. The remaining items held the same placements for both countries.

In recent years in Taiwan, under the encouragement of policy and government, Taiwan's elementary schools have actively joined many international technology competitions; conversely, due to the low birth rates and factors related to international relations, Japan seems to be have a better situation than Taiwan in terms of attracting foreign students, and recruiting international students has become a major focus of internationalization 
education in Japan (see Table 2).

\subsection{Level of Correspondence between Goals of International Education and Activities}

Taiwanese and Japanese elementary school principals' comparison of the goals of international education and the methods used are presented in Figure 4.

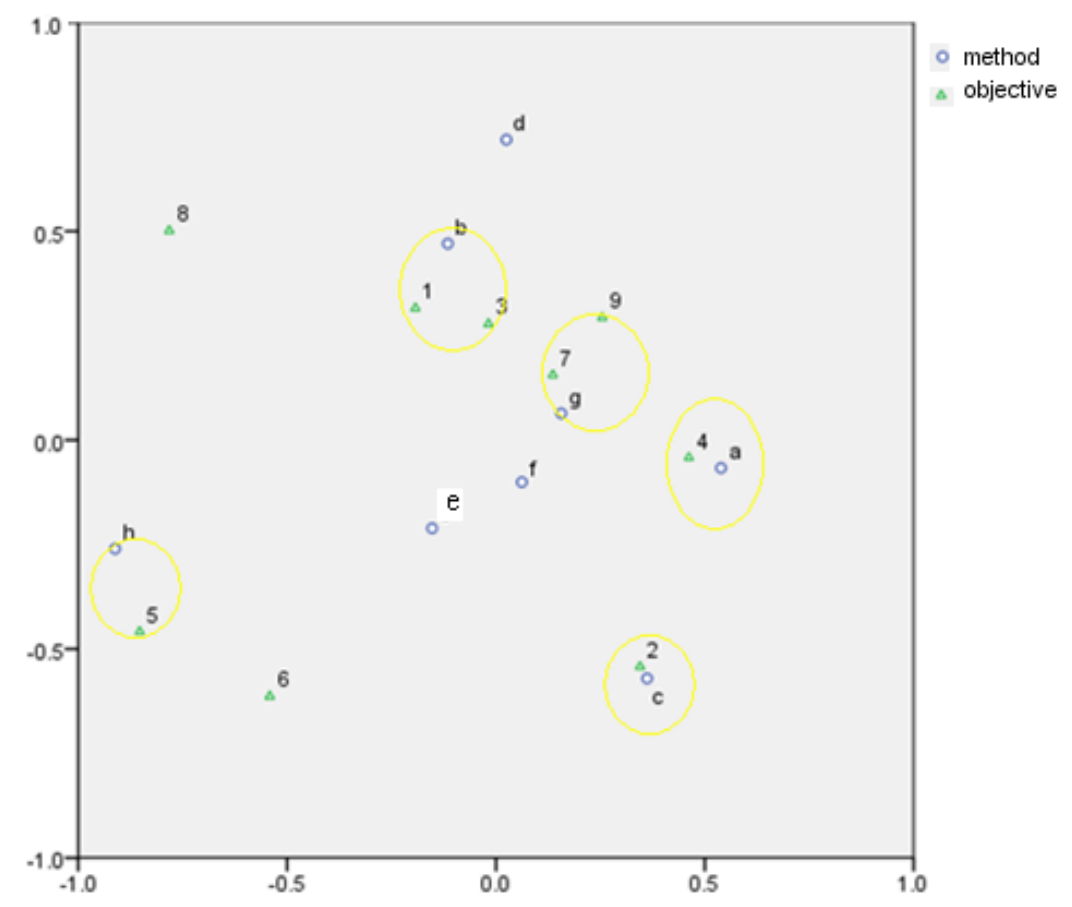

Figure 4. Correspondence between international education goals and methods

Note: (1) enhance student international knowledge; (2) improve students' foreign language communication skills; (3) inspire students' interest in international issues; (4) construct a multicultural learning environment; (5) obtain government subsidies or private sponsorship; (6) improve school recruitment competitiveness; (7) enhance student understanding of local culture; (8) consolidate student and teacher national consciousness; (9) cultivate an appreciation and tolerance for different cultures.

a. actively recruit international students; $b$. encourage staff to participate in various international education workshops; c. create a school-wide foreign language learning environment; d. integrate all kinds of international knowledge into the curriculum; e. establish outside school partnerships; f. routinely sponsor overseas study tours or visits; g. encourage domestic and international long-distance exchange students; h. join various international competitions.

In general, five types of correspondence exist among the data:

1) 5 and h: Schools obtaining more funding and assistance (5) can manage to participate in more international competitions (h).

2) 2 and c: For schools to improve student foreign language communication abilities (2), schools must pay attention to constructing a school-wide foreign language environment (c), the effects of which can be significant.

3) 4 and a: By constructing a multicultural environment (4), schools create a situation that is more conducive to recruiting international students (a).

4) 7,9 and g: Enhancing student understanding of the local culture (7) as well as fostering student appreciation and tolerance of other cultures (9) can be achieved by promoting domestic and international long-distance exchanges (g).

5) 1, 3 and b: To enhance students' level of international knowledge (1) and inspire student interest in international issues (3), schools can encourage staff to participate in a variety of international education 
workshops (b).

\section{Conclusion and Discussion}

This study of elementary school principals in Taiwan and Japan attempted to confirm the main factors involved in the implementation of internationalization of education, establish the importance of these factors, and determine the order of implementation of such factors during the implementation of international education in order to provide schools with working strategies to use in their own attempts at implementing international education policies.

The main goal of this study was to determine that Taiwan's Ministry of Education is currently actively promoting an international education policy in elementary and secondary schools and that elementary school principals believe that the most important benefits of the internationalization of education is for students. In Japan, efforts to internationalize education began earlier, and elementary school principals currently believe that goals to school organizations and institutions are the main priority. Perhaps as Taiwan is currently promoting internationalization of education policies and adequate funding is being provided for this, principals can focus their concerns exclusively on the influence of such policies on students; meanwhile, as Japan is not currently emphasizing such educational policies, principals from Japan instead value implementation of this educational policy in wider terms to ensure its benefits for school institutions. Principals in both countries ranked the goals of international education at the societal level last.

After analyzing the assigned weights, the study next found that, in implementing the internationalization of education in Taiwan, the most important aspects were enhancing students' international knowledge, improving students' foreign language communication skills, and inspiring student interest in international issues; for Japan, the most important aspects were constructing a multicultural learning environment, obtaining government grants or private sponsorship, and inspiring student interest in international issues. As it is a current focus of educational policy, Taiwan is injecting abundant funds toward internationalizing education, and the consequent focus of policy evaluation will be placed on the impact of policy on students. This is reflected in the study as the three most important items for elementary school principals in Taiwan are indeed at the student level. Taiwan is in the full swing of implementing an international education policy, and the effectiveness of student learning outcomes will often be evaluated; as a result, its scores seem high compared to Japan, where such policies are not currently being focused on. In contrast, as Lin (2008) stated, the internationalization of education in Japan has already become integrated into the school curriculum; therefore, the injection of more funds is limited. As a result, of the three items that elementary school principals in Japan value the most-namely, building a multicultural learning environment, obtaining government grants or private sponsorship, and inspiring student interests in international issues - two are concerned with the benefits of policy at the institutional level.

The third finding is that, for both countries, the performance of the practical implementation of international education is not adequate. Only three items - integrating a variety of international knowledge into the curriculum, creating a school-wide foreign language learning environment, and encouraging staff to participate in various international education workshops - are handled fairly well by both countries. Japan's scores for every other item are lower than Taiwan's. According to the literature (Fortuijn, 2002; Zheng et al., 2001), the implementation strategies for the internationalization of education in Taiwan and Japan are broadly in line with the experience of Western countries; in the execution of such policies, further efforts are needed. There are considerable differences between the official policy objectives of international education and school principals' practical understanding of such policy objectives.

Regarding the lowest scores for Taiwan, it is perhaps because international educational policies are currently being implemented; it is therefore easy for schools to get funding directly from the government as receiving public or private funds seems less important for the principals. Moreover, it is possible that Taiwanese elementary school principals might not see a direct positive correlation between the implementation of international education and the consolidation of national consciousness, thereby resulting in a lower score for this item.

As for Japan, basic literacy is emphasized in compulsory education; international education is included primarily at the higher levels of education and is not a primary focus of the elementary and middle school curriculum development. As a result, schools can only rarely receive government funding for efforts to promote the internationalization of education at the elementary and middle school levels. Unlike their Taiwanese counterparts, Japanese principals do not feel that a relationship exists between the implementation of international education and the development of national consciousness; therefore, this item received a lower score. Perhaps the principals of both countries consider that achieving the goal of "consolidating national consciousness" cannot be 
achieved through the internationalization of education.

Furthermore, the differing goals for the internationalization of education can be achieved by applying various strategies. Schools wishing to attend more international competitions, for example, can obtain funding for grants. An emphasis on establishing a school-wide foreign language learning environment can improve students' foreign language communication skills. Schools wishing to recruit international students should establish a multicultural environment, and promoting domestic-international exchanges between schools can increase students' understanding of the local culture as well as foster their appreciation and tolerance of other cultures. Finally, encouraging staff to participate in various international education workshops will both broaden students' international knowledge and inspire students' interest in international issues.

Special attention should be paid to the following result: Taiwanese and Japanese principals agree that the implementation of international educational activities are unable to achieve the goal of consolidating national consciousness, yet this goal is considered an important part of the Taiwan Ministry of Education's white paper on international education, which states that, "in the promotion of international education in primary and secondary schools, through a comparison of international cultures schools can educate students to more deeply understand the unique features of their own local culture, to recognize the features of Taiwan's unique historical position, to realize the special situation of Taiwan's place in the international community, and to awaken their national consciousness and take up personal responsibility for their country" (Ministry of Education, 2011: 5).

Finally, this study suggests that the educational authorities of both countries explore the patterns that emerge on the diagram so as to choose the strategies that will be the most effective and will have the greatest correspondence with local goals.

\section{References}

Adam, M. (2003). World climate demands global learning for all. Education Digest, 69(3), 25-30.

Ali, A. K., \& Doan, P. L. (2006). A Survey of undergraduate course syllabi and a hybrid course on global urban topics. Journal of Planning Education and Research, 26(2), 222-236.

Altbach, P. G. (2004). Globalization and the university: Myths and realities in an unequal world. Tertiary Education and Management, 10, 3-25.

Asia Society. (2008). Going global: Preparing our students for an interconnected world. New York: The council of chief state school officers. Retrieved from http://AsiaSociety.org/Education

Bunnell, T. (2010). The momentum behind the international primary curriculum in schools in England. Journal of Curriculum Studies, 42(4), 471-486. http://dx.doi.org/10.1080/00220272.2010.487315

Dronkers, J. (1993). The causes of growth of English education in the Netherlands: Class or internationalization? European Journal of Education, 28(3), 295-307.

Fortuijn, J. D. (2002). Internationalising learning and teaching: A European experience. Journal of Geography in Higher Education, 26(3), 263-273. http://dx.doi.org/10.1080/0309826022000019855

Gurran, N., Norman, B., \& Gleeson, B. (2008). Planning education discussion paper: Prepared for the planning institute of Australia, January 2008. Retrieved from http://www.planning.org.au/documents/item/67

Harman, G. (2004). New directions in internationalization higher education: Australia's development as an exporter of higher education services. Higher Education Policy, 17, 101-120. http://dx.doi.org/10.1057/palgrave.hep.8300044

Howe, D. (2008). Schools without walls. Phi Delta Kappan, 90(3), 206-210.

Knight, J. (2003). Updating the definition of internationalization. International Higher Education, 33, 2-3.

Knight, J. (2005). An internationalization model: Responding to new realities and challenges. In H. de Wit, I. C. Jaramillo, J. Knight, \& J. Gacel-Avila (Eds.), Higher education in Latin America: The international dimension (pp. 1-38). Washington, DC: The World Bank.

Knight, J., \& de Wit, H. (1995). Strategies for internationalization of higher education: Historical and conceptual perspectives. In H. de Wit (Ed.), Strategies for internationalization of higher education (pp. 5-32). Amsterdam: EAIE.

Knight, J., \& de Wit, H. (Eds.). (1999). Quality and internationalization in higher education. Paris: OECD Publications.

Lin, M. (2008). Educational reform and development in Japan: Seen from the revision of the curriculum 
guidelines. Bulletin of National institute of educational resources and research, 40, 48-83.

Luxon, T., \& Peelo, M. (2009). Internationalization: Its implications for curriculum design and course development in UK higher education. Innovations in Education and Teaching International, 46(1), 51-60.

MEXT. (1989). Elementary school teaching guidelines. Retrieved from http://www.mext.go.jp/a_menu/shotou/old-cs/1322235.htm

MEXT. (2008). 300, 000 foreign students plan. Retrieved from http://www.mext.go.jp/b_menu/houdou/20/07/08080109.htm

Ministry of Education. (2001). Grade 1-9 curriculum guidelines. Taipei: MOE.

Ministry of Education. (2004). 2005-to-2008 education policy principles. Taipei: MOE.

Ministry of Education. (2011). A white paper on international education for primary \& secondary schools. Taipei: MOE.

Nukaga, M. (2003). Japanese education in an era of internationalization: A case study of an emerging multicultural coexistence model. International Journal of Japanese Sociology, 12, 79-94. http://dx.doi.org/10.1111/j.1475-6781.2003.00044.x

Okubo, Y. (2000). Japan: Internationalization of education. Human rights education in Asian schools, 3, 37-40.

Saaty, T. L. (1980). The analytic hierarchy process: Planning, priority, setting, resource allocation. New York: McGraw-Hill.

Saaty, T. L. (1994). Highlights and critical points in the theory and application of the analytic hierarchy process. European Journal of Operational Research, 74(3), 426-447.

Schoorman, D. (2000). How is internationalization implemented? A framework for original practice (Report No. HE033161). FL : Department of teacher education Florida Atlantic University (ERIC document reproduction service No. ED 444426).

Shaklee, B., \& Baily, S. (Eds.). (2012). Internationalizing teacher education in the United States. Lanham, MD: Rowman \& Littlefield Education Publishing Group.

Stewart, V. (2007). Becoming citizens of the world. Educational Leadership, 64(7), 8-14.

Stewart, V. (2008). World-Smart students. Phi Delta Kappan, 90(3), 203-205.

Svensson, L., \& Wihlborg, M. (2010). Internationalizing the content of higher education: The need for a curriculum perspective. Higher Education, 60(6), 595-613. http://dx.doi.org/10.1007/s10734-010-9318-6

Taylor, E. W. (1994). Intercultural competency: A transformative learning process. Adult Education Quarterly, 44(3), 154-174. http://dx.doi.org/10.1177/074171369404400303

Zheng, X. X., Hinshaw, A. S., Yu, M. Y., Guo, G. F., \& Oakley, D. J. (2001). Building international partnerships. International Nursing Review, 48, 117-121.

\section{Copyrights}

Copyright for this article is retained by the author(s), with first publication rights granted to the journal.

This is an open-access article distributed under the terms and conditions of the Creative Commons Attribution license (http://creativecommons.org/licenses/by/3.0/). 